\title{
Анализ качества социально-политических дискуссий в Интернете: тестирование методологии
}

\author{
Д. В. Волковский, О. Г. Филатова \\ Санкт-Петербургский государственный университет \\ daniil.volkovskii@yandex.com, o.filatovaespbu.ru
}

\section{Аннотация}

В статье представлены результаты исследования авторов, касающегося выявления различных параметров интернет-дискуссий. На основе углубленного анализа контента 11 онлайн-дискуссий, касающихся пенсионной реформы в России, авторы выявляют и оценивают основные параметры, касающиеся качества социально-политических интернет-дискуссий с точки зрения их делиберативности.

Выявление таких параметров позволяет сформулировать суть мнений участников дискурса в отношении различных общественных проблем (например, поддержки или отрицания пенсионной реформы). В итоге формируются массивы данных, связывающих оригинальный авторский текст постов с неким обобщенным мнением, что в дальнейшем позволит предсказывать тип мнений в зависимости от содержания текста, выявлять множественность и неоднозначность мнений, высказываемых людьми по актуальной теме. Наиболее подробным образом в статье анализируются такие параметры дискуссий, как аргументация и цивильность. Подробно представлена методика исследования, основанная на концепции Юргена Хабермаса, которая может быть использована в подобного рода исследованиях в дальнейшем.

Ключевые слова: электронное участие, делиберативный стандарт, дискурсивные параметры, интернет-делиберация, методология дискурс-анализа, аргументация, цивильность, пенсионная реформа

Библиографическая ссылка: Волковский Д.В., Филатова О.Г. Анализ качества социально-политических дискуссий в Интернете: тестирование методологии // Государство и граждане в электронной среде. Выпуск 4 (Труды XXIII Международной объединенной научной конференции «Интернет и современное общество», IMS-2020, Санкт-Петербург, 17 - 20 июня 2020 г. Сборник научных статей). - СПб: Университет ИТМО, 2020. С. 96-113. DOІ: 10.17586/2541-979Х-4-96-113

\section{1. Введение}

Современное интенсивное развитие цифровых технологий расширяет возможности для различных широких публичных дискуссий в Интернете. Постоянно расширяющееся цифровое пространство коммуникации чрезвычайно дискурсивно и интернет-дискуссии на различные социально-политические темы становятся все более значимым полем научноисследовательских интересов.

Ценность интернет-дискуссий заключается в том, что их участники могут артикулировать свои интересы, открыто выражать позиции по волнующей их проблематике и подкреплять их необходимыми аргументами, что способствует формированию качественного общественного мнения и достижению консенсуса [1]. При этом 
демократическая дискуссия должна быть «информированной, сбалансированной, сознательной, независимой и всесторонней» [2].

Утверждаются важными «компетентность в полемике, использование интеллекта общественности в государственных делах и непредвзятость в обретении истины» [3] для сохранения демократии и развития эффективной коммуникации между государством и гражданским обществом.

Исследовательская задача, на решение которой направлена работа, представленная в данной статье, заключается в том, чтобы на основе углубленного анализа контента онлайндискуссий выявить, оценить и апробировать основные параметры, касающиеся качества социально-политических интернет-дискуссий с точки зрения их делиберативности. Хотя теоретики делиберативной демократии выделяют правила и процедуры делиберативного обсуждения, в реальности у нас нет примеров и инструментов для проведения мониторинга дискурса и оценки уровня поляризации мнений.

В первой части статьи представлены теоретические основы работы, во второй части подробно описана методика проведенного исследования, позволяющая выявить ключевые параметры интернет-дискуссий, в третьей части на конкретном примере анализируются такие важные параметры дискуссий, как аргументированность и цивильность.

\section{2. Теоретические подходы к исследованию делиберативности интернет-дискурса}

В контексте нашего исследования важную роль играет, прежде всего, концепция делиберативности, подробно разработанная в теории коммуникативной этики Юргена Хабермаса [4]. рассматриваемая как повседневная практика политических онлайнобсуждений, которые возникают в связи с какими-то событиями и процессами в политической сфере как на локальном, национальном, так и на глобальном уровнях [5]. Делиберативность направлена на повышение гражданской активности, связанной с принятием решений по общественным вопросам, и формирование гражданскоориентированного характера коммуникации. Хабермас подчеркивал особое значение коммуникации между субъектами публичной сферы, которые ведут уважительный диалог на базе аргументации, главными условиями которой является публичность, равноправие, непринужденность и привлечение всех, кто желает высказать свое мнение

Вслед за Хабермасом мы рассматриваем Интернет как демократичную публичную площадку, на которой люди могут выражать свои мнения, взаимодействовать друг с другом и властью, поэтому большое значение приобретает такое понятие, как интернет-дискурс. В формулировке данного термина мы отталкиваемся от общего понятия «дискурс», которое исследователями трактуется по-разному, объединяя целую гамму значений. Известно, что в философии этот термин первым использовал еще Фома Аквинский, потом примерно в том же значении «интеллектуального рассуждения» его использовали Гоббс, Лейбниц, Кант, которые считали, что человеческая мысль в целом дискурсивна. Французские структуралисты и постструктуралисты - М. Фуко, А. Греймас, Ж. Деррида, Ю. Кристева рассматривали дискурс как способ говорения и изучали разные виды дискурса и «дискурсивных практик». Можно сказать, что во всех западноевропейских языках «популярное значение развивалось вокруг «ученой дискуссии» и затем перекочевало к «диалогу» [6, с. 46].

В отечественной научной среде понятие «дискурс» впервые было применено в 1970-е годы только в лингвистическом плане как текст или речь [7, с. 18]. В 1995 году в «Англорусском словаре лингвистики и семиотики» А.Н. Баранов и Д.О. Добровольский раскрывают термин «дискурс» с точки зрения логики, философии, социологии и социальной семиотики и рассматривают его как «вид речевой коммуникации, предполагающей рациональное критическое рассмотрение ценностей, норм и правил социальной жизни и единственным своим мотивом имеющий достижение взаимопонимания» [8]. По мнению 
известной российской исследовательницы Н.Д. Арутюновой, «дискурс - это речь, погруженная в жизнь» [9].

Итак, дискурс - это междисциплинарный феномен, который может изучаться с философской, лингвистической, социологической, исторической, политологической, коммуникационной и других точек зрения. В нашей работе мы опираемся на политическую и коммуникативную основы феномена, их взаимосвязь, рассматривая его как коммуникативное событие и коммуникативное действие.

Подход к дискурсу как к коммуникативному акту, коммуникативному событию демонстрируется Т.А. ван Дейком, который говорит о том, что дискурс - это «сложное единство языковой формы, значения и действия, которое соответствует понятию “коммуникативное событие”» [10, с. 46]. По его мнению, дискурс не является изолированной текстовой или диалогической структурой, это сложное коммуникативное явление, включающее в себя социальный контекст [10, с. 113]. Представления учёного имеют большое значение для понимания связи дискурса с политической сферой.

Мы солидарны с позицией Т.А. ван Дейка, по утверждению которого дискурс можно рассматривать в качестве конкретного разговора, его типа, социальной формации и жанра [11]. Обращаясь к последнему аспекту, политический дискурс определяется как политически ограниченный жанр, обладающий специфическими функциями [12].

Современные научные подходы к интерпретации политического дискурса разнородны. К примеру, известная бельгийская исследовательница К. де Ландтсшеер широко определяет политический дискурс как язык СМИ или других институтов, который используется в социальной и политической сферах коммуникации $[13,14]$. Большой интерес представляют научные работы таких современных зарубежных исследователей дискурса, как Э. Лакло и Ш. Муфф [15], Л. Дж. Филлипс и М.В. Йоргенсен [16]. В прадискурсивно ориентированной теории Д. Остина публичное политическое взаимодействие позволяет рассматривать дискурс не только как речевое политическое событие, но и как политическое действие [17].

Однако мы подробно не останавливаемся на особенностях собственно политического дискурса, поскольку больший интерес для нас представляет онлайн-дискурс. Базируясь на концепции делиберативности Ю. Хабермаса, в основе которой лежит формирование идеальной модели демократии с помощью совершенствования механизмов коммуникативного дискурса, мы можем уверенно считать его формой электронного участия в политике.

Онлайн-дискурс представляет собой дискурс публичного взаимодействия в интернете. Политический онлайн-дискурс является одновременно электронной политической средой и электронной политической жизнью человека, который может функционировать в нём как анонимно, так и открыто [18]. Мы рассматриваем политический интернет-дискурс (онлайндискурс, электронный дискурс) как один из инструментов связей с общественностью в политической сфере и в сфере государственного управления. Политический онлайндискурс может формировать и отражать настроения, позиции граждан, участвующих в нём, преследуя цели влияния на принятие политических решений, управления государственными делами, манипуляции, давления на государственные органы власти и т. п. Мы считаем, что представителям органов власти всех уровней, отвечающим за связи с общественностью, в первую очередь необходимо тщательно отслеживать современный интернет-дискурс по важным общественно-политическим вопросам, владеть методиками дискурс-анализа, создающего возможность выявить аргументацию и вычленить позиции дискутантов.

В целом изучение онлайн-дискурса представляется методологически и эмпирически сложной задачей. Множество учёных из разных стран прибегает к разным подходам его анализа.

Например, традиционными исследованиями дискурса в интернете, особенно с использованием методов сетевого анализа, известен Центр Беркмана по изучению 
интернета и общества Гарвардского университета, США (Брюс Этлинг, Карина Алексанян, Джон Келли, Роберт Фарис, Джон Палфрей и Урс Гассер).

Следует указать на исследования Фиореллы Де Синдио - профессора кафедры информатики и коммуникации Миланского университета, использующей философию Liquid Democracy для изучения политических процессов и разработки конкретных приложений, способствующих более осмысленным политическим дебатам и обратной связи с гражданами [19].

Эрик Шоуерс, Натан Тиндалл и Тодд Дэвис из Центра изучения языка и информации и Программы символических систем Стэнфордского университета в своих работах затрагивают проблему равенства участия и принятия решений в делиберативном процессе, сравнивая его с личной коммуникацией [20].

Коллеги Т. Дэвиса (Брендан О'Коннор, Алекс Кокран, Джонатан Дж. Эффрат, Эндрю Паркер, Бенджамин Ньюман, Аарон Тэм) рассматривают онлайн-среду демократического обсуждения, детализируя ее принципы, правила, модель и мотивацию, на примере специализированной платформы для онлайн-делиберации «Deme» (предназначена для того, чтобы группы людей могли участвовать в совместной разработке проектов, целенаправленном обсуждении и принятии решений с использованием интернета) [21].

Лу Сяо из Университета Западного Онтарио (Канада), Вейю Чжан из Национального университета Сингапура, Анна Пшибыльска из Университета Варшавы (Польша), Анна Де Лиддо из Открытого университета (Великобритания), Грегорио Конвертино из корпорации Informatica совместно занимаются технологиями и дизайном для интерактивных дискуссионных процессов, подчёркивая междисциплинарный характер исследований [22].

В России изучением отдельных аспектов данной проблематики занимаются несколько исследовательских коллективов. Например, большинство российских учёных, включая Е. И. Шейгал, О. Ф. Русакову, В. Г. Базылева, М. В. Гаврилову [23] при анализе интернетдискурса использует лингвистический подход и базируется на идеях М. Бахтина [24]. Учёные рассматривают дискурс как мощный ресурс, при помощи которого социальные субъекты позиционируют себя в политическом пространстве, активно отстаивают свои интенции и воплощают их. Другие исследователи, в частности, Ю.Г. Мисников, А.В. Чугунов анализируют онлайн-дискурс с точки зрения концепции делиберативной демократии Юргена Хабермаса. Мы также сфокусированы на этом направлении исследовательской мысли. Далее подробным образом описана методология дискурсанализа и представлены результаты аналитической работы. Некоторые результаты уже были продемонстрированы в других публикациях [25-28], однако в этой работе больше деталей и выводов.

\section{3. Описание методологии дискурс-анализа}

Наше исследование проводилось по методике анализа дискурса, разработанной и описанной Ю.Г. Мисниковым. Учёный разработал «Deliberative Standard to Assess Discourse Quality» [5] и описал семь тематически различных дискурсивных стандартов, соответствующих конкретным вопросам исследования, для руководства процессом кодирования сообщений интернет-дискуссий. Отметим, что Ю.Г. Мисников сделал это первым, так как на момент выхода его диссертации в научной литературе не существовало прямых аналогов. Каждый стандарт содержит набор конкретных эмпирических параметров, предназначенных для отражения определенных дискурсивных качеств.

Первый параметр коррелирует с партисипативным равенством и активностью в написании постов, содержащими семь характеристик: идентификация участника, имя, членский статус, идентификация поста, идентификация поста участника, совокупная идентификация постов, дата поста. При исследовании уровня активности граждан часто возникает проблема, связанная с неравномерным распределением долей участия в обсуждениях, что ухудшает качество дискуссии. Заметим, что превалирование высоко 
интерактивных, сильно персональных и часто невежливых обращений и комментариев в интернет-дискуссиях также приводит к их слабому, низкому, «неудовлетворительному» качеству.

Второй параметр раскрывает «цивильность» (вежливость), которая используется для характеристики качественного характера публичной онлайн-дискуссии и связана она с демонстрацией толерантного отношения. Данные о цивильности не так просто интерпретировать, поскольку нет универсального подхода к её определению. Бывают ситуации, когда сообщения содержат одновременно вежливые и невежливые речевые аспекты, что вызывает трудность в кодировке поста. Помимо использования грубых выражений, которые отчётливо демонстрируют умышлённую невежливость, некоторые сообщения могут только подразумевать неприятный подтекст. В некоторых случаях реакция субъектов онлайн-обсуждений на такие посты может выступать надёжным индикатором, отражающим всю сложность субъективных отношений, которые формируются между участниками в процессе дискуссий. Если говорить о вежливых сообщениях, то они могут иметь специальную цель и быть адресованы определённым участникам в более персонализированной манере или же с выделением акцентов на некоторых аспектах темы, что способствует большему вовлечению людей в обсуждение. В целом цивильность включает следующие тональности выражения отношения:

цивильные (экспрессивно вежливые, приветственные, необязательно поддерживающие, могут быть критичными);

нормальные (амбивалентные, нейтральные, могут как поддерживать, так и критиковать);

ацивильные (экспрессивно недружественные, пренебрежительные, враждебные, грубые, не обязательно критические);

- другие (их сложно квалифицировать, что-то смешанное между цивильными и ацивильными).

Следующий параметр - действенность утверждений: истинность высказываний, нормативная правота, субъективная правдивость, согласие и несогласие. В качестве ещё одного параметра указаны намерения речевых актов, которые могут быть директивными (чётко направленными, не подлежащими спору), коммиссивными (допускаются некие поправки и корректировки) и экспрессивными (носят преимущественно эмоциональный характер).

Значимыми составляющими обсуждений являются такие параметры, как дискурсивные интерактивность и диалогичность, охватывающие персонально адресованные посты с использованием имени адресата; не персонально адресованные; прямые ответы участников, включая цитаты; открытые ответы, обратную связь на сообщения и цитирование постов.

Диалогичность концептуально акцентирует внимание на окружающих. Если коммуникатор понимает их и знает, как найти к ним подход, то он лучше поймёт себя и свои коммуникативные действия. Однако, когда концепт «Я» спрятан в концепт «Другие», когда самореализация идёт через других, то тут и возникает сложность. Наши изречения нельзя определить как первоначальные или конечные, все они имеют предварительную историю и одновременно содержат предчувствие, связанное с реакциями других на то, что сказано или написано. Диалог - это распознавание нужд и интересов других через взаимность, которая включает не только согласие, но и оппозицию, противоречие. Когда есть обратная связь, аргументация, возражение субъектов дискурса, диалогические отношения между ними становятся более значимы, ибо избегают пассивное состояние. Рядом с понятием диалогичности находится понятие интерактивности, которую принято считать ключом к изучению публичных онлайн-дискурсов. Одним из её преимуществ является то, что не требуется, чтобы участники, вовлеченные в публичный диалог, встречались лицом к лицу. Интерактивность не обязательно стимулирует публичное взаимодействие индивидов. Скорее всего это возможность быть диалогичным и кооперативным с равными себе людьми, что привлекает остальных граждан к участию в онлайн-дискурсе. Несогласия, полемика 
рассматриваются как часть интерактивности в том числе. Существует спор насчёт того, кого из участников интернет-дискуссии можно считать интерактивным: того, кто отвечает только на предыдущее сообщение, или того, кто отвечает на многие сообщения. Мы считаем, что те и те будут являться интерактивными участниками, однако степень их интерактивности будет значительно различаться.

Аргументация, как существенный аспект при изучении онлайн-дискуссий, изменчива, многогранна, никогда не находится в статичном состоянии, направлена прежде всего на обеспечение понимания между участниками обсуждений и поддержание диалога между ними при каждом взаимодействии. Аргументация всегда важна, так как она помогает увидеть «крайние позиции», т. е. позиции согласия и несогласия, выступающие, в свою очередь, демократическими формами публичного рассуждения посредством межличностной интеракции.

Аргументирование является актом взаимного понимания между коммуникаторами и обоюдного признания других индивидов и их позиций. Соответственно, аргументация на взаимной основе, по сути, выступает как коммуникативная и дискурсивная. Качество аргументации зависит не столько от говорящего, сколько от слушающего, поскольку нет смысла там, где нет диалога. Значение приобретает та коммуникация, в которой происходит ответ общественности на волнующие её проблемы, в ином случае коммуникативный акт становится бесполезным и бесчувственным [24]. Изолированные дискурсы не будут иметь практически никакого смысла для анализа, особенно в поляризированных социальнополитических взаимоотношений, поскольку их участники не в достаточной степени представляются риторически убедительными и диалогически адаптивными [29].

Согласно Ю.Г. Мисникову, аргументация как дискурсивный стандарт включает два набора параметров: первый из них содержит факты, выводы, примеры, сравнения, обобщения, логические умозаключения, другие виды доказательств, второй - ссылки на онлайн-ресурсы, печатные медиа, радио и телевидение. Именно с этих позиций мы проанализировали аргументацию в онлайн-дискуссиях на тему пенсионной реформы.

И, наконец, последний параметр - тематическое многообразие. Вопросы обсуждения могут быть связаны с государством и его управлением, обществом и политикой, экономикой, социальными проблемами, регионами, международными отношения в пределах бывшего СССР и, далее, с культурой, здравоохранением, стилем жизни, медиа и интернетом.

Данная методика дискурсивного анализа, основанная на концепции Хабермаса и развивающая её, была выбрана по нескольким причинам. Во-первых, она позволяет выявлять коммуникативную и социально-политическую стороны онлайн-дискурса, изучать его с позиций политического PR, политической коммуникации. Во-вторых, методика является понятной и несложной, ей удобно пользоваться в программе Excel. К данному методологическому подходу могут прибегать эксперты, PR-специалисты, обычные граждане, что расширяет сферу дискурсивного анализа, делает её разнообразной с точки зрения участников и придаёт демократичности с позиций общественного контроля. При изучении каждого комментария интернет-дискуссии ему присваивается свой уникальный числовой идентификатор в виде комбинации трех параметров: (1) уникальный идентификатор сообщения, закодированный (начиная с 1) в последовательном порядке публикации независимо от автора (последняя цифра представляет общее количество опубликованных высказываний всех участников); (2) уникальный идентификатор участника, закодированный (начиная с 1) в порядке начала обсуждения (последняя цифра представляет общее количество всех участников); (3) уникальный идентификатор высказывания, закодированный (начиная с 1) в последовательном порядке публикации каждым участником (последняя цифра представляет общее количество опубликованных высказываний каждым участником). Таким образом, каждое опубликованное сообщение может быть однозначно идентифицировано с помощью трехзначной комбинации с точки зрения того, когда оно было отправлено, кем и в каком порядке. Другие атрибуты 
(например, статус участника форума или дата регистрации) могут быть добавлены по мере необходимости. Например, сообщение, закодированное как «12-4-2», означает, что это было 12-е сообщение в ветке, опубликованной участником, который вступил в дискуссию под номером 4, и это была его или ее вторая публикация до сих пор.

В-третьих, ручной подсчёт некоторых данных и их кодировка постепенно может быть автоматизирован, что заметно ускорит и облегчит работу исследователя, особенно когда количество постов превышает тысячи. Работы в данном направлении уже проводятся в рамках исследовательского проекта с участием авторов статьи.

В-четвёртых, использование методики позволяет сформулировать суть мнений участников дискурса в отношении различных общественных проблем. В итоге формируются массивы данных, связывающих оригинальный авторский текст постов с неким обобщенным мнением, что в дальнейшем позволит предсказывать тип мнений в зависимости от содержания текста, выявлять множественность и неоднозначность мнений, высказываемых людьми по актуальной теме.

Несмотря на преимущества методики, у неё есть и минусы. Например, они связаны с репрезентативностью результатов, насколько они истинны и отражают реальную картину коммуникативной ситуации, насколько их можно считать аргументированными и подлинными. К тому же существует проблема идентификации характеристик дискутирующих персон, групп общественности, что важно учитывать при принятии политических решений.

\section{4. Исследование интернет-дискуссий на тему увеличения пенсионного возраста}

В декабре 2018 - январе 2019 был проведён анализ интернет-дискуссий на тему увеличения пенсионного возраста российскими властями. Анализ проводился в несколько раундов. Результаты первых двух раундов уже были представлены ранее [25-28].

Для исследования мы отобрали интернет-площадки 11 разных по численности населения российских городов, где обсуждалась тема повышения пенсионного возраста. В итоговую выборку попали Москва, Санкт-Петербург и Волгоград (крупнейшие города по классификации Минэкономразвития РФ), Калининград и Севастополь (крупные), Братск и Нальчик (большие), Белореченск и Снежинск (средние), Боровичи и Урюпинск (малые). Когда мы отбирали городские интернет-форумы для анализа онлайн-дискуссий, наши исследовательские интересы столкнулись с некоторыми ограничениями. Было установлено, что не у всех российских городов есть форумы, где ведутся обсуждения на социальнополитические проблематики, в частности, пенсионной реформы. Часто на найденных интернет-площадках, где обсуждалось повышение пенсионного возраста, количество комментариев было меньше 100 - этот факт вызывает дополнительные ограничения на выборку. В результате всего было проанализировано 5405 постов, размещенных 454 участниками.

На первых этапах исследования были получены данные о том, какое количество людей в процентном соотношении выступает за повышение пенсионного возраста, а какое против. Эти данные сравнивались с результатами социологического опроса на аналогичную тему, проведенного Фондом «Общественное мнение» 26-27 мая 2018 г. в 53 субъектах РФ (1500 респондентов [30]) (см. таблицу 1).

По результатам социологического опроса ФОМ общее число людей, относящихся отрицательно к идее повышения пенсионного возраста, составляет 92,4\%. Этот показатель отличается от показателя, полученного нами в ходе анализа онлайн-дискуссий $(89,6 \%)-$ соответственно, участники интернет-обсуждений менее отрицательно относятся к пенсионной реформе. Причем в Москве, крупнейших, крупных и малых городах уровень негативного отношения к реформе меньше среднего уровня негативного отношения (92,35\%), зафиксированного в социологическом опросе. 
Таблица 1. Отношение к пенсионной реформе, 2018 г. (в процентах)

\begin{tabular}{|l|c|c|}
\hline \multicolumn{1}{|c|}{ Позиция } & 3а реформу & Против \\
\hline Результаты анализа онлайн-дискуссий & 10,40 & 89,60 \\
Результаты опроса ФОМ & 7,65 & 92,35 \\
\hline
\end{tabular}

Говоря о конкретных городах и сравнивая показатели негативного отношения участников на их интернет-площадках с общим процентом, установлено, что в Волгограде, Севастополе, Братске, Нальчике, Белореченске, Снежинске и Урюпинске уровень отрицательного отношения выше среднего $(89,6 \%)$, в то время как в Москве, СанктПетербурге, Калининграде и Боровичах ниже. Любопытно, что в Снежинске уровень негатива участников онлайн-дискурса достигает $100 \%$.

Однако заметим, что большинство участников дискуссий оставляют по 10 и более комментариев, что в значительной степени влияет на подсчет голосов. Например, наши данные по Москве практически полностью совпали с данными ФОМ, так как участники московского форума оставляли в основном всего лишь по одному комментарию (только один участник оставил более 10 комментариев). Более того, общий процент негативного отношения в больших и средних городах $(94,25 \%)$, выявленный в ходе анализа дискуссий, почти совпал с процентом социологического опроса (95\%), но нужно учитывать, что мы суммировали данные по большим (92,5\%) и средним городам (96\%), чтобы прийти к общему выводу $(94,25 \%)$. С другими форумами ситуация иная, что объясняется наличием небольшого количества участников и большого числа размещенных ими постов. В дальнейших исследованиях на этот факт важно обращать особое внимание, так как при соблюдении равенства соотношения участников и созданных ими комментариев данные об общественном мнении людей будут более точными, их качество и значимость будут выше.

Сравнение с социологическими данными, полученными в тот же период, дает основание сделать важное заключение: граждане, участвующие в обсуждении проблемы являются более мотивированными, а, возможно, и более информированными, осведомлёнными, чем среднестатистический участник социологического опроса. Получается, что участники интернет-дискуссий демонстрируют более взвешенную позицию, чем общий негативный настрой, выявленный в результате репрезентативного социологического опроса.

На первом этапе исследования мы также рассмотрели такой параметр «делиберативного стандарта», как активность участников дискуссий, чтобы проверить, насколько соблюдается равенство участников в обсуждении и есть ли доминирующие участники дискуссии. Подтвердилась наша гипотеза о том, что большое число людей, принимающих участие в обсуждении вопросов на интернет-площадках, пишет относительно небольшое количество постов и небольшая часть - много сообщений. В ходе исследования активности участников мы выделили пять групп: малоактивные (1 пост), умеренно активные (2-3), активные (4-5), очень активные (6-9) и гиперактивные (более 10 постов). Далее исследовалась зависимость между активностью участников и формированием их позиции в отношении пенсионной реформы, т. е. проверялась гипотеза о связи позиции «за»или «против» с количеством комментариев, оставленных интернет-пользователями. Об этом более подробно можно прочитать в нашей предыдущей статье [27]. Там же представлены и итоги второго раунда исследований, связанных с тестированием возможностей искусственного интеллекта применительно к исследованию интернет-дискуссий.

На третьем этапе мы продолжили углубленное тестирование методики и прежде всего исследовали зависимость между активностью участников и аргументацией их позиции в отношении пенсионной реформы. Было выявлено, что около $70 \%$ постов (минимальное количество постов на одного пользователя - 10, максимальное - 176) принадлежит гиперактивным участникам (интересно, что их доля составила $18 \%$ от всех участников), соответственно, их аргументация играет большую роль, чем аргументация остальных 
категорий участников ввиду количественного показателя. Далее аргументация гиперактивных участников была проанализирована по следующим позициям:

- субъективные выводы, анализ, умозаключения, рассуждения, обобщения, кроме заявлений без объяснений;

субъективные действия, рекомендации, предложения;

любые примеры, случаи, сравнения, события, даты, крылатые выражения;

объективные факты (повествовательные, количественные);

ссылки на политических деятелей (подразумеваются их действия);

- ссылки на различные источники, включая онлайн-ресурсы, печатные медиа, радио и телевидение.

Общий процент аргументации составил около 44,7\% от всех постов, однако стоит упомянуть, что некоторые посты содержали несколько типов аргументации, некоторые содержали только один, в остальных аргументации не было. Больше всего использовались выводы, обобщения и рассуждения, связанные с повышением пенсионного возраста, последствиями реформы (см. рис. 1). Любопытно, что участники интернет-дискуссий часто ссылались на политических деятелей (к примеру, Путин, Медведев, Зюганов, Грудинин, Навальный, Матвиенко, Кудрин, Собчак, Брежнев, Ельцин, Горбачёв, Ленин), и различные информационные ресурсы (около 95\% составили онлайн-источники, среди которых, социальные сети (преимущественно Facebook, Twitter, VKontakte и YouTube), онлайн-медиа (в основном статьи и высказывания политических деятелей), сайты политических партий (Единая Россия, КПРФ) и отдельных политиков (Навальный), статистические онлайнресурсы, нормативно-правовые документы; ТВ и печатные СМИ упоминались крайне редко).

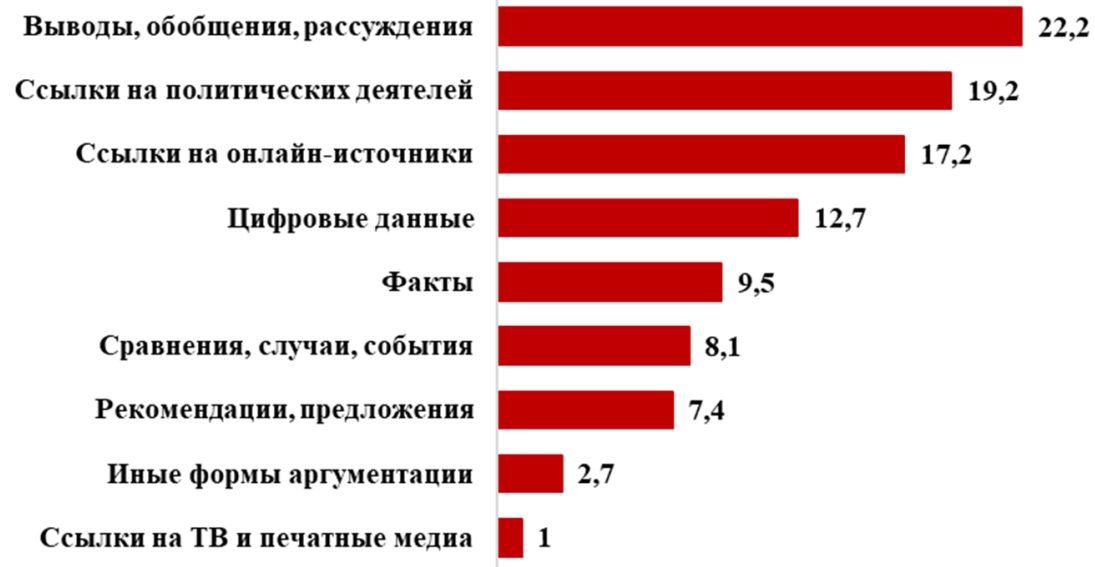

Рис. 1. Соотношение типов аргументации на основе анализа всех онлайн-дискуссий

Мы оценили уровень аргументации гиперактивных участников онлайн-дискуссий, взяв за основу тип городов согласно классификации (см. табл. 2).

Данные получились неоднозначными. Например, большие $(47,7 \%)$ и малые $(76,4 \%)$ города имеют проценты выше среднего $(44,7 \%)$, в то время как проценты крупнейших $(32,5 \%)$, крупных $(17,3 \%)$ и средних $(42,1 \%)$ городов ниже. Самый высокий уровень аргументации зафиксирован в малых городах, что объясняется относительно хорошим количеством участников, которые вели дискуссию по пенсионному вопросу (доминирующей формой аргументации выступали факты и цифровые показатели). Другую картину можно заметить в уровне аргументации крупных городов. 
Таблица 2. Уровни аргументации гиперактивных участников на онлайн-платформах разных по численности российских городов

\begin{tabular}{|l|l|l|l|l|l|}
\hline \multirow{2}{*}{ Показатели и уровни аргументации } & \multicolumn{5}{|c|}{ Тип городов } \\
\cline { 2 - 7 } & $\begin{array}{c}\text { Крупне } \\
\text { йшие }\end{array}$ & Крупные & Большие & Средние & Малые \\
\hline Число гиперактивных участников (чел.) & 12 & 9 & 15 & 24 & 20 \\
Факты, цифровые данные, примеры, & 17,8 & 9,4 & 24,2 & 20,7 & 36,0 \\
случаи, упоминания политиков (\%) & & & & & \\
Выводы, обобщения, рекомендации (\%) & 7,7 & 6,8 & 13,8 & 9,0 & 32,2 \\
Ссылки на онлайн и оффлайн-источники & 7,0 & 1,1 & 9,7 & 12,4 & 8,2 \\
(\%) & & & & & \\
Общий \% всех видов аргументации & 32,5 & 17,3 & 47,7 & 42,1 & 76,4 \\
\hline
\end{tabular}

Количество участников было самым низким, но это не послужило причиной такого низкого показателя. Дело в том, что в Калининграде $(83 \%)$ был найден самый высокий уровень интерактивности среди участников, которые направляли свои силы и мысли не на обсуждение пенсионного вопроса, а на выяснения личных отношений. Дискуссии между этими участниками наполнены диалогичными формами, негативом, оскорблениями и руганью, что, безусловно, значительно повлияло на аргументацию, заменённую выражением эмоций. Вместо конструктивного диалога, подразумевающего качественную аргументацию, мы столкнулись с эмоциональностью, никаким образом не коррелирующей с рациональностью.

Мы предполагаем, что уровень аргументации частично зависит от цивильности и её характеристик. Можно утверждать, что аргументация и цивильность - первостепенные дискурсивные параметры (на наш взгляд, аргументация - самая значимая часть в обсуждениях), поскольку они могут выступать катализаторами или ингибиторами интерактивности, партисипативной активности и т. п. Поэтому аргументация и цивильность - качественные параметры, которые могут оказывать колоссальный позитивный или негативный эффект на дискурс и его направленность, в то время как интерактивность количественный и зависимый параметр.

Мы проанализировали цивильность, зафиксированную в делиберациях на тему пенсионной реформы, с трёх позиций:

1) интерперсональный характер = посты прямо адресованы другим участником с упоминанием имени или личных обращений:

- (a) посты не касаются проблематик, т. е. они исключительно имеют персонализированный характер (эта категория включает только фразы или предложения с указанием на межличностные характеристики и любые другие коммуникации (нейтральные в том числе));

- (b) посты явно грубые и оскорбительные по отношению к человеку, национальности, религии, идеологии и т. д. (отличать от иронии, юмора, сарказма);

- (c) посты явно вежливые и уважительные по отношению к человеку (могут содержать иронию, юмор, сарказм в позитивном аспекте);

2) посты не включают явного упоминания имени участника, могут быть прямо или косвенно адресованы определённой персоне, кому-то иному или всем людям:

- (d) посты содержат грубые, оскорбительные выражения, лексику (ирония, юмор и сарказм исключены из этой категории);

- (е) посты явно вежливы и уважительны (включают намеренную вежливость, иронию, юмор, сарказм неоскорбительного характера);

3) посты прямым или косвенным образом посвящены пенсионной реформе:

(f) посты касаются темы, но грубые по отношению к человеку;

(g) посты по теме, но грубы, безличны.

Общий процент цивильности составил около 50,61\% от всех постов, однако необходимо добавить, что некоторые посты содержали несколько типов цивильности, некоторые - 
только один, остальные не имели ничего. Тематически пустые посты (с указанием имени пользователя и без прямого или косвенного упоминания пенсионной реформы) $(42,23 \%)$ составили наибольшее число постов, содержащих цивильность (см. рис. 2). Меньше всего было постов по теме, при этом, грубых по отношению к человеку $(4,03 \%)$.

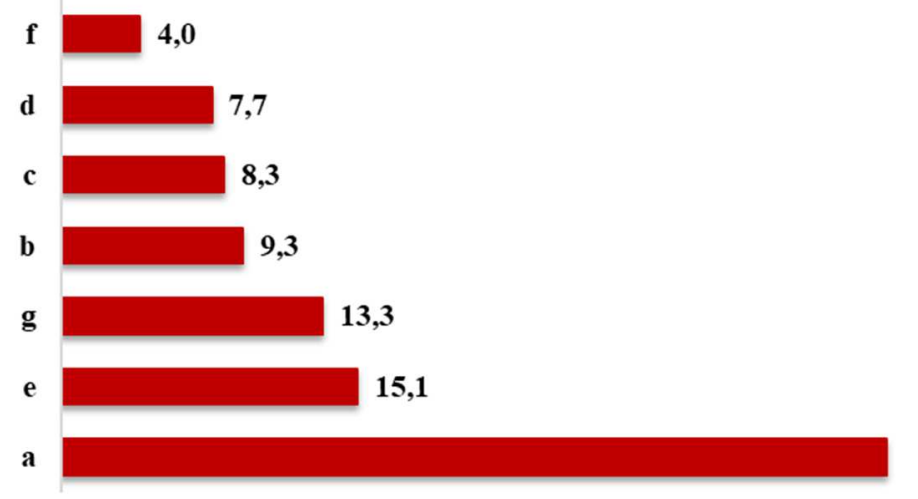

Рис. 2. Разделение типов цивильности на основе анализа всех дискуссий

Если мы попытаемся объяснить полученные данные по аргументации, основываясь на данных различных типов цивильности, мы можем заметить, что коммуникаторы преимущественно использовались тематически пустые посты. Следовательно, это может выступать причиной низких уровней аргументации в некоторых городах. Однако важно детально рассмотреть делиберации на форумах каждого города и каждой классификации отдельно, поскольку они имеют свои особенности и представляют иногда противоположные коммуникативные миры.

Мы также использовали классификацию городов при анализе уровней цивильности (см. таблицу 3). Самый высокий показатель цивильности был у крупнейших городов (78,94\%). Большие и малые города имели почти одинаковые данные $(73,53 \%$ и 76,4\% соответственно). Самые низкие показатели уровней цивильности у больших и средних городов (34,12\% и 26,87\% соответственно). Интересно понять, почему мы можем увидеть три различных модели цивильности. Для этого обратимся к данным по аргументации.

Во-первых, начнём с больших и средних городов. Уровни аргументации больших $(47,7 \%)$ и средних $(42,1 \%)$ городов были очень близки среднему показателю $(44,7 \%)$. Их уровни цивильности были почти в полтора раза меньше уровней аргументации. Здесь берётся во внимание числовой показатель.

Вторая модель связана с городами, где были отмечены низкие уровни аргументации: крупнейшие $(32,5 \%)$ и крупные $(17.3 \%)$. Можно предположить, что из-за недостатка хорошего качества аргументов уровни цивильности на форумах этих городов были выше среднего. Поэтому далее необходимо будет проверить гипотезу о взаимозависимости аргументации и цивильности: чем ниже уровень аргументации, тем выше уровень цивильности и наоборот. Но есть некоторые моменты, которые нельзя исключать. Например, качество и интенсивность аргументов в постах, процент постов межличностного характера, не касающихся темы дискуссии.

Третья модель любопытна своей двойственностью. К примеру, в крупнейших и крупных городах высокие уровни цивильности, в то время как их уровни аргументации одни из самых низких. Проценты постов, которые были прямо адресованы другим участникам с помощью упоминания имени, на форумах этих городов были высоки (крупнейшие - 63,5\% из 78,94\%, крупные - 48,68\% из 73,53\%). Эти данные значительно влияют на общие показатели цивильности и аргументации. Если мы сравним их с данными малых городов, где были зафиксированы одинаково высокие уровни аргументации $(76,4 \%)$ и цивильности 
(76,4\%), то увидим, что тенденция отличается. Процент интерперсональных постов без упоминания темы составил $49,86 \%$, но участники на форумах малых городов создавали больше постов, содержащих несколько типов аргументации одновременно. Это может быть причиной, по которой частично объясняется такой высокий показатель цивильности. Количество постов с аргументацией был не огромным, но интенсивность аргументов была высока в обсуждениях на онлайн-платформах малых городов.

Таблица 3. Уровни цивильности всех участников на онлайн-площадках российских городов в соответствии с классификацией

\begin{tabular}{|c|c|c|c|c|c|}
\hline \multirow[b]{2}{*}{ Уровень цивильности постов } & \multicolumn{5}{|c|}{ Тип городов } \\
\hline & $\begin{array}{l}\text { Крупней- } \\
\text { шие }\end{array}$ & Крупные & Большие & Средние & Малые \\
\hline $\begin{array}{l}\text { Интерперсональный характер постов = } \\
\text { посты прямо адресованы другим } \\
\text { участником с упоминанием имени или } \\
\text { личных обращений }\end{array}$ & 63,5 & 48,7 & 10,8 & 4,9 & 49,9 \\
\hline $\begin{array}{l}\text { Посты не включают явного упоминания } \\
\text { имени участника, могут быть прямо или } \\
\text { косвенно адресованы определённой } \\
\text { персоне, кому-то иному или всем людям }\end{array}$ & 8,0 & 15,6 & 14,3 & 10,2 & 10,2 \\
\hline $\begin{array}{l}\text { Посты прямым или косвенным образом } \\
\text { посвящены пенсионной реформе }\end{array}$ & 7,4 & 9,2 & 11,7 & 11,7 & 2,7 \\
\hline Все типы цивильности & 78,9 & 73,5 & 34,1 & 26,9 & 76,4 \\
\hline
\end{tabular}

Приходится согласиться с уже полученными ранее выводами других исследований о том, что «даже если политические дискуссии в Интернете более тонкие и гражданские, чем дискуссии по другим вопросам», они, как правило, далеки от рационального гражданского обсуждения, о котором говорил Хабермас [29]. Участники часто отвлекаются от основной темы обсуждения, используют неуважительные и даже оскорбительные формулировки и нападения ad hominem, делают заявления, не подкрепленные аргументами, или полностью воздерживаются от рациональной аргументации, и используют свое социальное положение в данной платформе для делегитимизации противоположных взглядов.

\section{5. Заключение}

Итак, используемая методика дискурсивного анализа позволила выявить ключевые параметры интернет-дискурса. Базируясь на делиберативной концепции Ю. Хабермаса, в основе которой лежит формирование идеальной модели демократии с помощью совершенствования механизмов коммуникативного дискурса, мы можем уверенно считать его формой электронного политического участия. На различных цифровых платформах участия граждане находят точки соприкосновения по поводу решений тех или иных проблем, их преодоления в результате различных переговоров, дискуссий, которые являются предпосылкой дискурсивной демократии.

Благодаря обмену мнениями, взглядами, позициями по различным социальнополитическим проблематикам формируются общественный диалог, дискуссии, выступающие в качестве публичного политического дискурса. Делиберации в онлайнпространстве позволяют участникам проявлять политическое творчество, поэтому в данном случае нужно указать на попытку вторичной социализации и самореализации в социуме, связанной с невозможностью открыто рассуждать на острые политические темы и быть услышанным властью. Интернет-дискурс можно охарактеризовать как технологически и творчески глубоко индивидуальный, эмоционально экспрессивный, отражающий ситуативный и хаотичный характер публичных коммуникативных потоков, мгновенность и 
сиюминутность речевого поведения участников, невосприимчивость социальных, этических норм публичной политической интеракции [7, с. 243].

Некоторые участники онлайн-дискурса считают политические интернет-дискуссии не существенными, в то время как другие полагают, что подобные обсуждения в электронной среде способы улучшить качество публичной дискуссии, поскольку «асинхронные пространства для обсуждения, в которых есть время подумать над ответом, дать гиперссылку на базовую информацию, а также цифровые платформы, созданные для стимулирования диалогических форм коммуникации, могут открыть возможности для более информированной демократической дискуссии» [31, с. 76].

Говоря о политической коммуникации в интернет-пространстве, обратим внимание на два противоположных вывода, которые делает известный английский исследователь С. Коулман. Первый вывод связан со средой коммуникации: в онлайн-среде, диалог в которой чётким образом спроектирован, поведенческие характеристики участников больше соответствуют демократическим нормам, чем если бы дискуссии разворачивались между ними в офлайн-среде [32]. Более того, в процессе онлайн-обсуждений участники более открыты к использованию широкого репертуара аргументов, что с большей вероятностью может привести к изменению их точки зрения и большей рефлексии после окончания делиберации [33]. Однако если существуют значительные идеологические разногласия во взглядах, то качество онлайн-дискурса сильно снижается, что находит сходство с аналогично поляризованными офлайн-пространствами [34; 35].

Второй вывод касается того, можно ли политические онлайн-обсуждения считать значимыми, способными влиять на разработку определённого политического курса и принятия решений. Было отмечено, что делиберации на политические темы действительно редко интегрируются в институциональные процессы принятия решений» [31, с. 77], большинство участников находятся, метафорически говоря, за каменной стеной и не могут достучаться до власти, поэтому возникает ощущение, как будто они разговаривают сами с собой. Иногда в онлайн-дискуссиях обнаруживаются интересные идеи, глубоко аргументированные позиции, убедительные примеры из практики, сочетание противоположных точек зрения, но принимающие решения лица используют все эти ценные компоненты качественной делиберации лишь символически. Поэтому ценность интернет-дискуссий многими участниками онлайн-дискурса подвергается большому сомнению, в то время как государственные учреждения используют онлайн-консультации, обычно не включающие аспекты широко распространённого в социальных сетях неформального общения или элементы структурированной делиберации в публичном пространстве, что редко приводит к активному взаимодействию, диалогичной форме коммуникации между гражданами. Важно сказать, что, когда интернет-дискуссии неформальны, импровизированы и не поддерживаются делиберативной инфраструктурой, коммуникативное поведение участников больше приближено к делиберативным нормам, чем это ожидается [36-38].

Прямую коммуникацию между властью и сообществами, индивидами вслед за С. Коулманом можно называть «новым методом медиации отношений граждан и представителей» [31, с. 81], поскольку интернет позволяет органам государственной власти укреплять собственную легитимность через постоянные коммуникационные отношения с гражданами, которые активно принимают участие в формулировке политических решений и их принятии.

На сегодняшний день «граждане желают и в большей степени готовы к политическому дискурсу» [39], но для того, чтобы полностью реализовать идеи коммуникативной демократии, необходимо работать над развитием процедур организации свободных собраний граждан, совершенствовать механизмы политического дискурса, без которых не получится нормализовать демократический процесс.

Для того, чтобы интернет-дискуссии по-настоящему имели общественный вес и представляли для их участников ценность, власть должна учитывать преимущества таких 
обсуждений, вкладывать финансовые и технологические ресурсы, направленные на повышение качества дискуссий и взаимодействия между гражданами. При этом должны быть обеспечены и условия для реализации таких дискуссий, в том числе возможности открыто и без страха рассуждать на острые политические проблемы, предлагать пути их решения.

Конечно, необходимо и дальше проводить исследования в данном контексте, ориентированные на изучение факторов, способствующих эффективному функционированию системы электронного взаимодействия между властью и гражданами. Методика исследования, представленная в статье, может быть усовершенствована. Направления дальнейших исследований преимущественно связаны с совершенствованием возможностей для развития технологий автоматизированной обработки дискуссий, их анализа, выявлением реальных пользователей и ботов, специальных накруток. После решения этой проблемы откроются новые перспективы, ускорятся процессы исследований обсуждений. Например, можно будет объяснить чрезмерную активность пользователей, качество и количество аргументов, что повысит ценность дискуссий как коммуникативнополитического ресурса, подразумевающего вовлечение граждан в политическое участие, управление и решение значимых общественных вопросов. Представляется, что описанная методика позволит в дальнейшем определять проблемы и выявлять направления работы для специалистов по коммуникациям в органах власти, что, в свою очередь, расширит число участников интернет-дискуссий, разнообразит содержание обсуждений и стимулирует коммуникацию между властными структурами и институтами гражданского общества, отдельными гражданами.

Работа выполнена при поддержке РНФ, проект №18-18-00360 «Электронное участие как фактор динамики политического процесса и процесса принятия государственных решений».

\section{Литература}

[1] Театр политического дискурса за кулисами и на сцене. URL: http://mognovse.ru/lhjteatr-politicheskogo-diskursa-za-kulisami-i-na-scene.html (дата обращения: 22.02.2020).

[2] Fishkin J., Luskin R. Experimenting with a Democratic Ideal: Deliberative Polling and Public Opinion // Acta Politica. 2005. Vol. 40. P. 285. DOI: 10.1057/palgrave.ap.5500121.

[3] Хелд Д. Модели демократии. М.: Издательский дом «Дело» РАНХиГС, 2014. 544 с.

[4] Habermas J. Moral consciousness and communicative action. Cambridge: Polity Press, 1992. $242 \mathrm{p}$.

[5] Misnikov Y. Public Activism Online in Russia: Citizens' Participation in Webbased Interactive Political Debate in the Context of Civil Society. Development and Transition to Democracy: PhD thesis ... Ph. D. / Y. Misnikov. Leeds, 2011.

[6] Тичер С., Мейер М., Водак Р., Веттер Е. Методы анализа текста и дискурса. Харьков: Изд-во Гуманитарный центр, 2009. 356 с.

[7] Клюев Е.В. Политический дискурс в массовой коммуникации: анализ публичного политического взаимодействия. М.-Берлин: Директ-Медиа, 2016. 263 с.

[8] Баранов А.Н., Добровольский Д. О. Англо-русский словарь лингвистики и семиотики. М., 1995. $642 \mathrm{c.}$

[9] Арутюнова Н.Д. Дискурс // Лингвистический энциклопедический словарь. М.: Сов. энциклопедия, 1990. С. 136-137.

[10] Дейк Т.А., ван. Язык. Познание. Коммуникация. М., 1989. 312 с.

[11] Dijk T.A. What is political discourse analysis? Amsterdam, 1998. P. 124-142.

[12] Dijk T.A. Political discourse and Political Cognition // Politics as Text and Talk: Analytic Approaches to Political Discourse. Amsterdam and Philadelphia, 2002. P. 203-237.

[13] De Landsheer Ch. Introduction to the Study of Political Discourse. 1998. P. 1-16. 
[14] De Landtsheer Ch. The political rhetoric of a United Europe. New York: Praeger Publishers, 1998. P. 35-51.

[15]Laclau E., Mouffe Ch. Hegemony and Socialist Strategy: Towards a Radical Democratic Politics. London; New York, 2001.

[16] Филлипс Л.Дж., Йоргенсен М. В. Дискурс-анализ: теория и метод. Харьков, 2004. $336 \mathrm{c}$.

[17] Austin J. L. How to do Things with Words: The William James Lectures Delivered at Harvard University in 1955. Oxford, 1962.

[18] Клюев Е.В. Политический дискурс в массовой коммуникации: анализ публичного политического взаимодействия. М.-Берлин: Директ-Медиа, 2016. 263 с.

[19] De Sindio F. Guidelines for Designing Deliberative Digital Habitats: Learning from eParticipation for Open Data Initiatives // The Journal of Community Informatics. 2012. Vol. 8,№2. URL: http://ci-journal.net/index.php/ciej/article/view/918/910 (дата обращения: 22.02.2020).

[20] Showers E., Tindall N, Davies T. R., Equality of Participation Online versus Face to Face: An Analysis of the Community Forum Deliberative Methods Demonstration (June 9, 2015). URL: https://ssrn.com/abstract=2616233 DOI: 10.2139/ssrn.2616233 (дата обращения: 19.02.2020).

[21] Davies T. R. O'Connor B. T., Cochran A., Effrat J., Parker A., Newman B., Tam A. An Online Environment for Democratic Deliberation: Motivations, Principles, and Design (October 15, 2009). Online deliberation: design, research, and practice. P. 275-292, Todd Davies, Seeta Peña Gangadharan, ed., CSLI Publications/University of Chicago Press, October 2009. URL: https://ssrn.com/abstract=2222850 (дата обращения: 20.02.2020).

[22]Xiao L., Zhang W., Przybylska, A., De Liddo A., Convertino G., Davies T., Klein M. Design for Online Deliberative Processes and Technologies: Towards a Multidisciplinary Research Agenda // Conference Paper. 33rd Annual ACM Conference Extended Abstracts on Human Factors in Computing System. 2017. p. 865-868.

[23] Русакова О. Ф., Максимов Д. А. Политическая дискурсология: предметное поле, теоретические подходы и структурная модель политического дискурса // Полис. 2006. №4. C. 27.

[24] Бахтин М. М. Проблема текста в лингвистике, филологии и других гуманитарных науках. М.: Искусство, 1986. С. 297-325.

[25] Волковский Д.В., Филатова О.Г. Дискуссии в интернете как форма электронного участия в политике: региональный аспект // PR и реклама в изменяющемся мире: региональный аспект. 2019. № 20-21. С. 6-16.

[26]Filatova O.G., Volkovskii D.V. The socio-political discourse in the era of digital transformations: the experience of Internet discourse research // La communication actuelle: le discours de transformations. Paris, 2019. Р. 8-18.

[27] Филатова О. Г., Мисников Ю. Г., Волковский Д. В., Беген П. Н. Электронное участие как общественно-политический дискурс: методы и направления исследований // Труды XXII Международной объединенной научной конференции «Интернет и современное общество», IMS-2019, Санкт-Петербург, 19 - 22 июня 2019 г. Сборник научных статей. СПб, 2019. С. 102-115.

[28] Волковский Д. В., Филатова О. Г. Интернет-дискурс как форма электронного участия: методология исследования на примере дискуссий о пенсионной реформе // Матэрыялы 21-й Міжнароднай навукова-практычная канфеоэнцыі. Мінск. 2019. С. 400-405.

[29] Habermas J. The Theory of Communicative Action. Reason and the Rationalization of Society. Vol. 1. Beacon, Boston, 1984. 516 p.

[30] О пенсионном возрасте и отношении к идее его повысить // Фонд «Общественное мнение». URL: https://fom.ru/posts/14043 (дата обращения: 17.02.2020).

[31] Коулман С. Может ли Интернет укрепить демократию? Пер. с англ. / С. Коулман; науч. ред. Ю. Г. Мисников, А. В. Чугунов. - СПб: Алетейя, 2018. 131 с. 
[32]Fricss D., Eilders C. A Systematic Review of Online Deliberation Research // Policy \& Internet. 2015. Vol. 7 (3). P. 319-339.

[33]Baek Y. M., Wojcieszak M., Michael X., Carpini D. Online versus Face-to-Face Deliberation: Who? Why? What? With What Effects? // New Media \& Society. 2012. P. 363-383.

[34]Matthew W., Daniels H., Daniels J. Racist Comments at Online News Sites: A Methodological Dilemma for Discourse Analysis // Media, Culture \& Society. 2013. Vol. 35 (3). P. 332-347.

[35]Rowe I. Civility 2.0: A Comparative Analysis of Incivility in Online Political Discussion // Information, Communication \& Society. 2015. Vol. 18 (2). P. 121-138.

[36]Manosevitch E., Steinfeld N., Lev-On A. Promoting Online Deliberation Quality: Cognitive Cues Matter // Information, Communication \& Society. 2014. Vol. 17 (10). P. 1177-1795.

[37]Svensson J. Participation as a Pastime: Political Discussion in a Queer Community Online // Javnost - The Public. 2015. Vol. 22 (3). P. 283-297.

[38]Wright S., Graham T., Jackson D. Third Space, Social Media and Everyday Political Talk // The Routledge Companion to Social Media and Politics. 2016. P. 74-88.

[39]Белоусова В. М. Делиберативная концепция Ю. Хабермаса в контексте систематизации современных моделей демократии // Вестник Удмуртского университета. Серия «Экономика и право». 2015. №4. С. 84-91.

\title{
Key Parameters of Online Discussions: Using Discursive Analysis Techniques
}

\author{
D. Volkovskii, O. Filatova
}

\section{St. Petersburg State University}

The article presents the results of a study by the authors regarding the identification of various parameters of online discussions. Based on an in-depth analysis of the content of 11 online discussions related to pension reform in Russia, the authors identify and evaluate the main parameters regarding the quality of socio-political Internet discussions in terms of their deliberation.

The identification of such parameters allows us to formulate the essence of the opinions of the participants in the discourse regarding various social problems (for example, supporting or denying pension reform). As a result, data arrays are formed that connect the original author's text of the posts with a certain generalized opinion, which in the future will make it possible to predict the type of opinions depending on the content of the text, to reveal the multiplicity and ambiguity of opinions expressed by people on a relevant topic. In the most detailed way, the article analyzes such parameters of discussions as argumentation and civility. The research methodology based on the concept of Jürgen Habermas, which can be used in similar studies in the future, is presented in detail.

Keywords: electronic participation, deliberative standard, discursive parameters, Internet deliberation, discourse analysis methodology, argumentation, civility, pension reform

Reference for citation: Volkovskii D., Filatova O. Key Parameters of Online Discussions: Using Discursive Analysis Techniques // The State and Citizens in the Electronic Environment. Vol. 4 (Proceedings of the XXIII International Joint Scientific Conference «Internet and Modern Society», IMS-2020, St. Petersburg, June 17-20, 2020). - St. Petersburg: ITMO University, 2020. P. 96-113. DOI: 10.17586/2541-979X-4-96-113 


\section{Reference}

[1] Teatr politicheskogo diskursa za kulisami i na scene. URL: http://mognovse.ru/lhjteatr-politicheskogo-diskursa-za-kulisami-i-na-scene.html (data obrashcheniya: 22.02.2020).

[2] Fishkin J., Luskin. R. Experimenting with a Democratic Ideal: Deliberative Polling and Public Opinion // Acta Politica. 2005. Vol. 40. P. 285. DOI: 10.1057/palgrave.ap.5500121.

[3] Held D. Modeli demokratii // M.: Izdatel'skij dom «Delo» RANHiGS, 2014. 544 s.

[4] Habermas J. Moral consciousness and communicative action. Cambridge: Polity Press, 1992. $242 \mathrm{p}$.

[5] Misnikov Y. Public Activism Online in Russia: Citizens' Participation in Webbased Interactive Political Debate in the Context of Civil Society. Development and Transition to Democracy: PhD thesis ... Ph. D. / Y. Misnikov. Leeds, 2011.

[6] Ticher S., Mejer M., Vodak R., Vetter E. Metody analiza teksta i diskursa. Har'kov: Izdvo Gumanitarnyj centr, 2009. $356 \mathrm{c}$.

[7] Klyuev E.V. Politicheskij diskurs v massovoj kommunikacii: analiz publichnogo politicheskogo vzaimodejstviya. M.-Berlin: Direkt-Media, 2016. $263 \mathrm{c}$.

[8] Baranov A. N., Dobrovol'skij D. O. Anglo-russkij slovar' lingvistiki i semiotiki. M., 1995. $642 \mathrm{c}$.

[9] Arutyunova N.D. Diskurs // Lingvisticheskij enciklopedicheskij slovar'. M.: Sov. enciklopediya, 1990. S. 136-137.

[10]Dejk T. A., van. YAzyk. Poznanie. Kommunikaciya. M., 1989. 312 c.

[11]Dijk T.A. What is political discourse analysis? Amsterdam, 1998. R. 124-142.

[12]Dijk T A. Political discourse and Political Cognition // Politics as Text and Talk: Analytic Approaches to Political Discourse. Amsterdam and Philadelphia, 2002. R. 203-237.

[13]De Landsheer Ch. Introduction to the Study of Political Discourse. 1998. R. 1-16.

[14]De Landtsheer Ch. The political rhetoric of a United Europe. New York: Praeger Publishers, 1998. R. 35-51.

[15]Laclau E., Mouffe Ch. Hegemony and Socialist Strategy: Towards a Radical Democratic Politics. London; New York, 2001.

[16]Fillips L. Dzh., Jorgensen M. V. Diskurs-analiz: teoriya i metod. Har'kov, 2004. 336 c.

[17]Austin J. L. How to do Things with Words (Slovo kak dejstvie): The William James Lectures Delivered at Harvard University in 1955. Oxford, 1962.

[18]Klyuev E.V. Politicheskij diskurs v massovoj kommunikacii: analiz publichnogo politicheskogo vzaimodejstviya. M.-Berlin: Direkt-Media, 2016. 263 c.

[19] De Sindio F. Guidelines for Designing Deliberative Digital Habitats: Learning from eParticipation for Open Data Initiatives // The Journal of Community Informatics. 2012. Vol. 8, №2. URL: http://ci-journal.net/index.php/ciej/article/view/918/910 (data obrashcheniya: 22.02.2020).

[20] Showers E., Tindall N, Davies T. R., Equality of Participation Online versus Face to Face: An Analysis of the Community Forum Deliberative Methods Demonstration (June 9, 2015). URL: https://ssrn.com/abstract=2616233 DOI: 10.2139/ssrn.2616233 (data obrashcheniya: 19.02.2020).

[21]Davies T. R. O'Connor B. T., Cochran A., Effrat J., Parker A., Newman B., Tam A. An Online Environment for Democratic Deliberation: Motivations, Principles, and Design (October 15, 2009). Online deliberation: design, research, and practice. P. 275-292, Todd Davies, Seeta Peña Gangadharan, ed., CSLI Publications/University of Chicago Press, October 2009. URL: https://ssrn.com/abstract=2222850 (data obrashcheniya: 20.02 .2020 ).

[22]Xiao L., Zhang W., Przybylska, A., De Liddo A., Convertino G., Davies T., Klein M/ Design for Online Deliberative Processes and Technologies: Towards a Multidisciplinary Research Agenda // Conference Paper. 33rd Annual ACM Conference Extended Abstracts on Human Factors in Computing System. 2017. p. 865-868. 
[23] Rusakova O.F., Maksimov D.A. Politicheskaya diskursologiya: predmetnoe pole, teoreticheskie podhody i strukturnaya model' politicheskogo diskursa // Polis. 2006. №4. S. 27.

[24]Bahtin M.M. Problema teksta v lingvistike, filologii i drugih gumanitarnyh naukah. M.: Iskusstvo, 1986. S. 297-325.

[25] Volkovskij D.V., Filatova O. G. Diskussii v internete kak forma elektronnogo uchastiya v politike: regional'nyj aspekt // PR i reklama v izmenyayushchemsya mire: regional'nyj aspekt. 2019. № 20-21. S. 6-16.

[26]Filatova O.G., Volkovskii D.V. The socio-political discourse in the era of digital transformations: the experience of Internet discourse research // La communication actuelle: le discours de transformations. Paris, 2019. P. 8-18.

[27]Filatova O.G., Misnikov YU.G., Volkovskij D. V., Begen P. N. Elektronnoe uchastie kak obshchestvenno-politicheskij diskurs: metody i napravleniya issledovanij // Trudy XXII Mezhdunarodnoj ob"edinennoj nauchnoj konferencii «Internet i sovremennoe obshchestvo», IMS-2019, Sankt-Peterburg, 19 - 22 iyunya 2019 g. Sbornik nauchnyh statej. SPb, 2019. S. 102-115.

[28]Volkovskij D.V., Filatova O.G. Internet-diskurs kak forma elektronnogo uchastiya: metodologiya issledovaniya na primere diskussij o pensionnoj reforme // Materyyaly 21j Mizhnarodnaj navukova-praktychnaya kanfeoencyi. Minsk. 2019. S. 400-405.

[29] Habermas J. The Theory of Communicative Action. Reason and the Rationalization of Society. Vol. 1. Beacon, Boston, 1984. 516 p.

[30]O pensionnom vozraste i otnoshenii k idee ego povysit" // Fond «Obshchestvennoe mnenie». URL: https://fom.ru/posts/14043 (data obrashcheniya: 17.02.2020).

[31]Koulman C. Mozhet li Internet ukrepit' demokratiyu? Per. s angl. / C. Koulman; nauch. red. YU. G. Misnikov, A. V. CHugunov. - SPb: Aletejya, 2018. 131 c.

[32] Fricss D., Eilders C. A Systematic Review of Online Deliberation Research // Policy \& Internet. 2015. Vol. 7 (3). P. 319-339.

[33] Baek Y. M., Wojcieszak M., Michael X., Carpini D. Online versus Face-to-Face Deliberation: Who? Why? What? With What Effects? // New Media \& Society. 2012. P. 363-383.

[34] Matthew W., Daniels H., Daniels J. Racist Comments at Online News Sites: A Methodological Dilemma for Discourse Analysis // Media, Culture \& Society. 2013. Vol. 35 (3). P. 332-347.

[35] Rowe I. Civility 2.0: A Comparative Analysis of Incivility in Online Political Discussion // Information, Communication \& Society. 2015. Vol. 18 (2). P. 121-138.

[36] Manosevitch E., Steinfeld N., Lev-On A. Promoting Online Deliberation Quality: Cognitive Cues Matter// Information, Communication \& Society. 2014. Vol. 17 (10). P. 1177-1795.

[37] Svensson J. Participation as a Pastime: Political Discussion in a Queer Community Online // Javnost - The Public. 2015. Vol. 22 (3). P. 283-297.

[38] Wright S., Graham T., Jackson D. Third Space, Social Media and Everyday Political Talk // The Routledge Companion to Social Media and Politics. 2016. P. 74-88.

[39] Belousova V.M. Deliberativnaya koncepciya YU. Habermasa v kontekste sistematizacii sovremennyh modelej demokratii // Vestnik Udmurtskogo universiteta. Seriya «Ekonomika i pravo». 2015. №4. S. 84-91. 